\title{
Analysis on the Choice Behavior for Graduation Whereabouts of University Student---Based on SEM
}

\author{
He Yiqing ${ }^{1,2, a}$, Xiao Yao ${ }^{1, b}$, Wan Min², Lv Xian² \\ ${ }^{1}$ School of Economics and Management, Nanchang University, Nanchang, 330031, China \\ ${ }^{2}$ Finance and Securities Research Institute, Nanchang University, Nanchang, 330031, China \\ aemail:hyq991@sohu.com, bemail: beckxy@126.com
}

Keywords: University Student; Graduation Whereabouts; Choice Behavior; SEM(Structural
Equation Model). Abstract. University student is an important part of social labor force in the future and their choice behaviors after graduation are the focus of common concern from all circles of society. The authors of this paper have investigated a mass of universities and colleges in Jiangxi province and made a SEM (Structural and Equation Model) to analyze the questionnaires. Through the analysis, the authors have worked out a path-road which can explicate how university students make the choice behavior for graduation whereabouts. Finally, the authors give out suggestions on education department, entrepreneur support and employment support from government.

\section{Introduction}

Employment, entrepreneurship and further study are the problems each university student will face, so the choice behaviors of university students determine the direction of their future development. Proper choice can make the university student avoid detours and achieve rapid success. If the choice behavior is not made properly, it will influence the university student's values of life. Wang Xilian(2001)[1] and Deng Shanshan (2004)[2] deem that blindness have made the postgraduate examination hot. In terms of employment, Yang Hongbing(2012)[3] considers that the university students need the spirit of bearing hardships. In terms of the university students themselves, Li Zaoshui and Li Guanghua (2012)[4] consider that they should enhance their abilities in many ways, such as strengthening professional technology, adjustment, self-exhibition, communication, collaboration and innovation. Xiao Han (2011)[5] believes that the specialized level of the employment guidance personnel in colleges and universities should be enhanced in order to provide better whole process employment guidance service for the students. Fang Zhou (2012)[6] argues that all these factors like students' abilities, traditional concepts, high financial costs, the imperfect financial services and the small scale of the enterprises they build lead to the difficulties of the university students' entrepreneurship. After looking into some literatures, the author discovered that there were few literatures on applying the structural equation model to study this problem and on comprehensively analyzing the choice behavior for graduation whereabouts of the university students. As a result, the research in the choice behavior for graduation whereabouts of the university students by means of structural equation model has both good academic value and application value.

The authors of this paper are through distribution of questionnaire, interview, questionnaire mail, and investigate a part of colleges and universities, such as Nanchang University, Jiangxi University of Finance and Economics, East China University of science and Technology, and Nanchang Hangkong University. We classify the factors influencing graduates' intention into personal information, environmental factor, individual endeavor and support factor and use the software of SPSS19.0 do the Cronbach's Alpha reliability test. Then, we use the software of amos17.0 to establish SEM through the process of modeling, calculating, model modifying, recalculating, model re-modifying. Finally we get the influencing path about the four factors above, analyze it in details and put out betterment countermeasures and suggestions.

\section{A brief description of the principle of the structural equation model}

Structural equation model is a multivariable test model which not only takes the internal structure 
of factors into consideration but also focus on the causality between the factors. It contains potentially immeasurable variables and belongs to test -modification model and is widely applied in the fields of society, economy and management. The model is as follows:

$$
\begin{aligned}
& X=\Lambda_{x} \xi+\delta \\
& Y=\Lambda_{y} \eta+\varepsilon \\
& \eta=B \eta+\Gamma \xi+\zeta
\end{aligned}
$$

In the above equations, (1) and (2) are the measurement models and are also called the confirmatory factor analysis models. $\Lambda_{x} 、 \Lambda_{y}$, which are also called loading matrix, are factor loadings; $\eta$ is an endogenous variable and $\xi$ is an exogenous variable. There is neither covariant relationship nor causal path between the variables $\delta$ and the residual errors $\varepsilon$ and equation (3), which is also called potential variable causal analysis model, is the structural model.

\section{Sources of the data and analysis of the survey results}

By group discussion and brain storming, this group lists the influencing factors as many as possible and designs the questions according to them to form a questionnaire.1000 questionnaires were distributed and 830 of them were successfully returned. The recovery rate reaches $83 \%$ and the effective rate $73.7 \%$.

\section{The index system and model establishment}

\begin{tabular}{|c|c|c|c|}
\hline Latent Variables & Observed Variables & Symbols & Corresponding Variance Symbol \\
\hline \multirow{7}{*}{$\begin{array}{c}\text { Personal } \\
\text { Information } \xi_{1}\end{array}$} & Gender & V1 & e1 \\
\hline & Subordinate Counties and Cities & V2 & e2 \\
\hline & Monthly Expense & V6 & e6 \\
\hline & Abilities and Specialties & V23 & e3 \\
\hline & $\begin{array}{l}\text { the Consideration on the Cost of } \\
\text { Employment、Entrepreneurship、 } \\
\text { Further Studies }\end{array}$ & V7 & e7 \\
\hline & Expected Income & V13 & e13 \\
\hline & Opportunity Cost & V35 & e35 \\
\hline \multirow{6}{*}{$\begin{array}{l}\text { Environmental } \\
\text { Factor } \xi_{2}\end{array}$} & $\begin{array}{c}\text { Degree of Selection Influenced } \\
\text { by People Around }\end{array}$ & V34 & e34 \\
\hline & View of Returnee & V18 & e18 \\
\hline & View of Self- entrepreneurship & V19 & e19 \\
\hline & $\begin{array}{l}\text { Cognition of } \\
\text { difficulty }\end{array}$ Entrepreneurship & V22 & e22 \\
\hline & $\begin{array}{l}\text { Disadvantage Factors on } \\
\text { Employment }\end{array}$ & V29 & e29 \\
\hline & Restraining Factors & V28 & e28 \\
\hline \multirow{4}{*}{$\begin{array}{c}\text { Individual } \\
\text { Endeavor } \xi_{3}\end{array}$} & Academic Record & V10 & e10 \\
\hline & Holiday Activity Degree & V25 & e25 \\
\hline & Employment Activity in School & V26 & e26 \\
\hline & Length of Employment Time & V12 & e12 \\
\hline \multirow{3}{*}{$\begin{array}{l}\text { Support Factor } \\
\qquad \eta_{1}\end{array}$} & Entrepreneurship Support Degree & V36 & e36 \\
\hline & Employment Guidance and Support & V37 & e37 \\
\hline & Help on Further Studies & V38 & e38 \\
\hline \multirow{2}{*}{$\begin{array}{c}\text { Final } \\
\text { Selection } \eta_{2}\end{array}$} & $\begin{array}{l}\text { the Choice of Employment、 } \\
\text { Entrepreneurship、Further Studies }\end{array}$ & V32 & e32 \\
\hline & Places Choice & V33 & e33 \\
\hline
\end{tabular}

The index system is presented as table 1 :

Table 1 The index system of factors influencing the college graduates' selection

Note: *The symbols of the index system are designed according to the questionnaires. 


\section{Empirical analysis}

Table 2 is the estimation of variables:

Table 2 The estimation of model to each variable

\begin{tabular}{|c|c|c|c|}
\hline \multicolumn{4}{|c|}{ Latent Variables } \\
\hline Personal Information & Environmental Factor & Individual Endeavor & Support Factor \\
\hline $2.202^{* *}$ & $0.208^{*}$ & $0.355^{*}$ & 0.026 \\
\hline \multicolumn{4}{|c|}{ Observed Variables } \\
\hline V1 & V2 & V6 & V7 \\
\hline 1 & $-7.929 * *$ & $3.897 * * *$ & $-2.41^{* *}$ \\
\hline V10 & V12 & V13 & V18 \\
\hline 1.045 & 1 & $1.273 *$ & 0.14 \\
\hline V19 & V22 & V23 & V25 \\
\hline$-0.816^{*}$ & 0688* & -0.041 & 16.702 \\
\hline V26 & V28 & V29 & V32 \\
\hline 6.065 & $-6.714^{* * *}$ & $-4.968 * * *$ & 1 \\
\hline V33 & V34 & V35 & V36 \\
\hline $1.003^{*}$ & 1 & $3.01 *$ & 1 \\
\hline V37 & V38 & & \\
\hline $1.349 * * *$ & $1.288 * * *$ & & \\
\hline \multicolumn{4}{|c|}{ correlation } \\
\hline \multicolumn{2}{|c|}{ Personal Information $\leftarrow \rightarrow$ Individual Endeavor } & \multicolumn{2}{|c|}{ Environmental Factor $\leftarrow \rightarrow$ Individual Endeavor } \\
\hline \multicolumn{2}{|c|}{-0.016} & \multicolumn{2}{|c|}{$0.546 *$} \\
\hline
\end{tabular}

Note: *means the estimation of parameter is significant under $10 \%$ level, ** is significant under $5 \%$ level, *** is significant under $1 \%$ level.

From Fig.1 and Table 3, college graduates' choice is comparably rational. In general, college graduates' choice is mainly according to their actual situation and abilities and also they would take some environment factors into consideration, such as the difficult degree of employment situation and postgraduate entrance exams and so on. The factor (such as individual endeavor) that is devoted to certain selection at school has great influence on college graduates' choice, but the influence is smaller than the personal information (direct effect is 2.202). Finally, supporting factor (direct effect is 0.026 ) is not significant at the level of $10 \%$. The possible reason may be the large number of students and the government and school only aid those brilliant graduates of the students. But others have little understanding on support subsidy. In addition, environment factor, such as employment situation, entrepreneurship condition, is significantly related with individual endeavor. This shows environmental factor would change graduates' activities at school and then influence final selection.

\section{Acknowledgement}

In this paper, the research was sponsored by the National Natural Science Foundation Project (No. 71063015 and No.71263039), Jiangxi Province's Project of Education and Teaching Reform for Degree \& Graduate Student and Nanchang University's Project for the Innovation Training of University Student in 2012.

About the author: He Yiqing (1961-), male, Professor, Doctoral Supervisor, Research Field: Finance and Education Economy.

\section{References}

[1]Wang Xilian. The Analysis of Graduate Going for Postgraduate Entrance Examination.[J]. Jiangxi Academy of Social Sciences, 2001(6)173-174. 
[2]Deng Shanshan. The reflection of graduates' self-value in “The Craze of Pursuing Graduate Studies” [J]. Hubei Academy of Social Sciences, 2004(3)134-135.

[3]Yang Hongbin. University Student Shouldn't Lose the Bear Spirit of Employment [J]. Education and Vocation, 2012(6)86.

[4]Li Zaoshui, Li Huaguang. Demand Analysis and Training on College Students' Employment Ability [J]. China's Adult Education, 2012(11)65-67.

[5]Xiao Han. Strengthen the Specialization of College Employment Guidance Staff and Upgrade the

Level of College Students' Employment work [J]. Journal of Southwest University for Nationalities (humanity and social science Version), 2011(S3)186-188.

[6]Fang Zhou. Thinking on the Financing Problem in Entrepreneurship of University Student in Gansu Province [J]. Research of Finance and Accounting, 2012(10)59-61. 